\title{
Porokeratotic adnexal ostial nevus: a paradigm of cutaneous mosaicism
}

\author{
Lisa Kiely ${ }^{1}$, Sarah Ní Mhaolcatha², Jim Fitzgibbon², Lesley-Ann Murphy ${ }^{1}$, and Cathal \\ $\mathrm{O}^{\prime}$ Connor ${ }^{1}$ \\ ${ }^{1}$ South Infirmary Victoria University Hospital \\ ${ }^{2}$ Cork University Hospital
}

February 20, 2022

\author{
Abstract \\ Porokeratotic adnexal ostial nevus (PAON) is a term encompassing porokeratotic eccrine ostial and dermal duct naevus \\ (PEODDN) and porokeratotic eccrine and hair follicle naevus (PEHFN). We present the case of a seven-year-old girl who \\ presented with hyperkeratotic verrucous papules in a blaschkolinear distribution on the sole of her left foot. \\ DR LISA KIELY (ORCID iD 0000-0003-1100-8692) \\ DR SARAH Ní MHAOLCATHA (ORCID iD 0000-0003-1831-4553) \\ DR JIM FITZGIBBON (ORCID iD 0000-0002-3899-8510) \\ DR LESLEY ANN MURPHY \\ DR CATHAL O'CONNOR (ORCID iD 0000-0001-7084-5293) \\ Case report \\ Porokeratotic adnexal ostial nevus: a paradigm of cutaneous mosaicism \\ Kiely L, ${ }^{1}$ Ni Maolcatha S, ${ }^{2}$ Fitzgibbon J, ${ }^{2}$ Murphy LA, ${ }^{1}$ O'Connor C, ${ }^{1,3}$ \\ 1 Department of Dermatology, South Infirmary Victoria University Hospital, Cork \\ 2 Department of Pathology, Cork University Hospital, Cork, Ireland \\ 3 Department of Paediatrics and Child Health, University College Cork, Cork, Ireland \\ Corresponding author: \\ Dr Cathal O'Connor \\ Department of Dermatology, South Infirmary Victoria University Hospital, Cork \\ Email: drcathaloconnor@gmail.com \\ Conflict of interest: None \\ Financial disclosure: None \\ Word Count: 581 \\ Figure Count: 2
}


Reference count: 5

Key words: PAON, PEODDN, Porokeratosis, Mosaicism

Written informed consent was obtained from the patient to publish this report in accordance with the journal's patient consent policy

\section{Introduction}

Porokeratotic adnexal ostial nevus (PAON) is a term that encompasses porokeratotic eccrine ostial and dermal duct naevus (PEODDN) and porokeratotic eccrine and hair follicle naevus (PEHFN). ${ }^{1} \mathrm{PAON}$ is a rare adnexal hamartoma characterized by the presence of a cornoid lamella exclusively overlying eccrine acrosyringia (the subype known as PEODDN) or over both eccrine acrosyringia and hair follicles (the subtype known as PEHFN).

\section{Case report}

A seven-year-old girl presented with hyperkeratotic verrucous papules in a blaschkolinear distribution on the sole of her left foot. The lesions were congenital and asymptomatic. She had a family history of atopic dermatitis but no significant past medical history. Prior to presentation, the lesions were treated with topical antifungals and salicylic acid, with no conferred benefit. On examination there were unilateral hyperkeratotic papules coalescing into plaques in a linear configuration following lines of Blashko on the lateral border of the left sole (Figure 1).

Histopathological analysis showed columns of parakeratosis associated with scant dyskeratotic keratinocytes in the upper granular layer reminiscent of cornoid lamellae (Figure 2). A deep infiltrate involving sweat ducts was absent.

\section{Discussion}

PAON is characterized by small discrete scaly papules arranged linearly, which may coalesce into plaques. Usually unilateral, most common sites are the palm or sole, with occasional extension onto the dorsae of the hands and feet, although more generalized eruptions have been reported. ${ }^{2}$ Lesions are typically asymptomatic. The male to female ratio is almost 1:1. ${ }^{2}$ PEODDN is usually a congenital phenomenon, however up to $26 \%$ of cases are reported to be late-onset, with some cases noted to develop following puberty. ${ }^{3}$ PEODDN usually becomes more warty in appearance over time.

PAON is a disorder of the intraepidermal eccrine duct (acrosyringium). Histopathology is diagnostic, characterized by parakeratotic columns within an epidermal invagination appearing as cornoid lamellae. Vacuolated and dyskeratotic keratinocytes are often present and there may be loss of the granular layer. ${ }^{4}$ Somatic mutations in GJB2 have been identified as causative in PAON, representing a mosaic form of keratosis ichthyosis deafness (KID) syndrome. GJB2 encodes the gap junction protein connexin26 (Cx26), which permits intercellular ion and macromolecule flux. ${ }^{5}$ Previously reported cases of PAON have described coexisting problems like seizures, hemiparesis, scoliosis, deafness, developmental delay, palmoplantar keratoderma, psoriasis, hyperthyroidism, polyneuropathy, breast hypoplasia and KID. ${ }^{2}$

The differential diagnosis of PAON includes variants of porokeratosis, naevus comedonicus, epidermal naevi, viral warts, or porokeratoma. Linear or punctate porokeratotosis lack the combination of cornoid lamellae with acrosyringia or hair follicle ostia, the eccrine duct hyperplasia and the thicker epidermal invagination. Naevus comedonicus and epidermal naevus (or inflammatory linear verrucous epidermal naevus) can rarely present with porokeratosis-like features, but are not related to eccrine ostia or hair follicle. Focal hyperparakeratosis, koilocytes and haemorrhagic exudates are seen in viral warts but not in PAON. In this case eccrine duct involvement was not clear on histology, but a diagnosis of PAON was favoured following clinicopathological correlation.

Current treatment options are of limited efficacy. Reported therapies include topical corticosteroids, topical salicylic acid, topical retinoids such as tazarotene, photodynamic therapy, and carbon dioxide laser. ${ }^{2,3}$ 
While the lesions tend to be refractory to treatment, they are usually asymptomatic and may not require intervention.

This case highlights a typical presentation of a rare condition whose clinical features are often initially subtle and can be easily overlooked. There is evidence that PAON is a manifestation of somatic mosaicism for KID syndrome and, although never previously reported, there is a theoretical risk of transmission of systemic disease to offspring.

\section{References}

1. Chowdhary B, Sharma A, Mahajan VK. Porokeratotic Eccrine Ostial and Dermal Duct Nevus and Porokeratotic Eccrine and Hair Follicle Nevus: Is Nomenclature "Porokeratotic Adnexal Ostial Nevus" More Appropriate?. Indian Dermatol Online J. 2019;10(4):478-480. doi:10.4103/idoj.IDOJ_341_18

2. Llamas-Velasco M, Hilty N, and Kempf W. Porokeratotic adnexal ostial naevus: review on the entity and therapeutic approach. J Eur Acad Dermatol Venereol, 2015; 29: 2032-2037. doi: 10.1111/jdv.12732

3. Alomran H, Kanitakis J. Adult-onset porokeratotic eccrine ostial and dermal duct nevus:dermatoscopic findings and treatment with tazarotene. Dermatol Online J. 2020;26(2):13030/qt1tf94054. Published $2020 \mathrm{Feb} 15$.

4. Sassmannshausen J, Bogomilsky J, Chaffins M. Porokeratotic eccrine ostial and dermal duct nevus: a case report and review of the literature. J Am Acad Dermatol. 2000;43(2 Pt 2):364-367. doi:10.1067/mjd.2000.100536

5. Levinsohn JL, McNiff JM, Antaya RJ, Choate KA. A Somatic p.G45E GJB2 Mutation Causing Porokeratotic Eccrine Ostial and Dermal Duct Nevus. JAMA Dermatol. 2015;151(6):638-641. doi:10.1001/jamadermatol.2014.5069

\section{Figure Legends}

Figure 1. Close-up view of the left plantar foot.

Figure 2. Microscopic sections of acral skin show papillary epidermal hyperplasia with alternating parakeratosis of the stratum corneum and orthokeratosis. Columns of parakeratosis in the troughs are associated with scant dyskeratotic keratinocytes, and loss of the granular cell layer beneath columns of parakeratosis reminiscent of a cornoid lamella. 


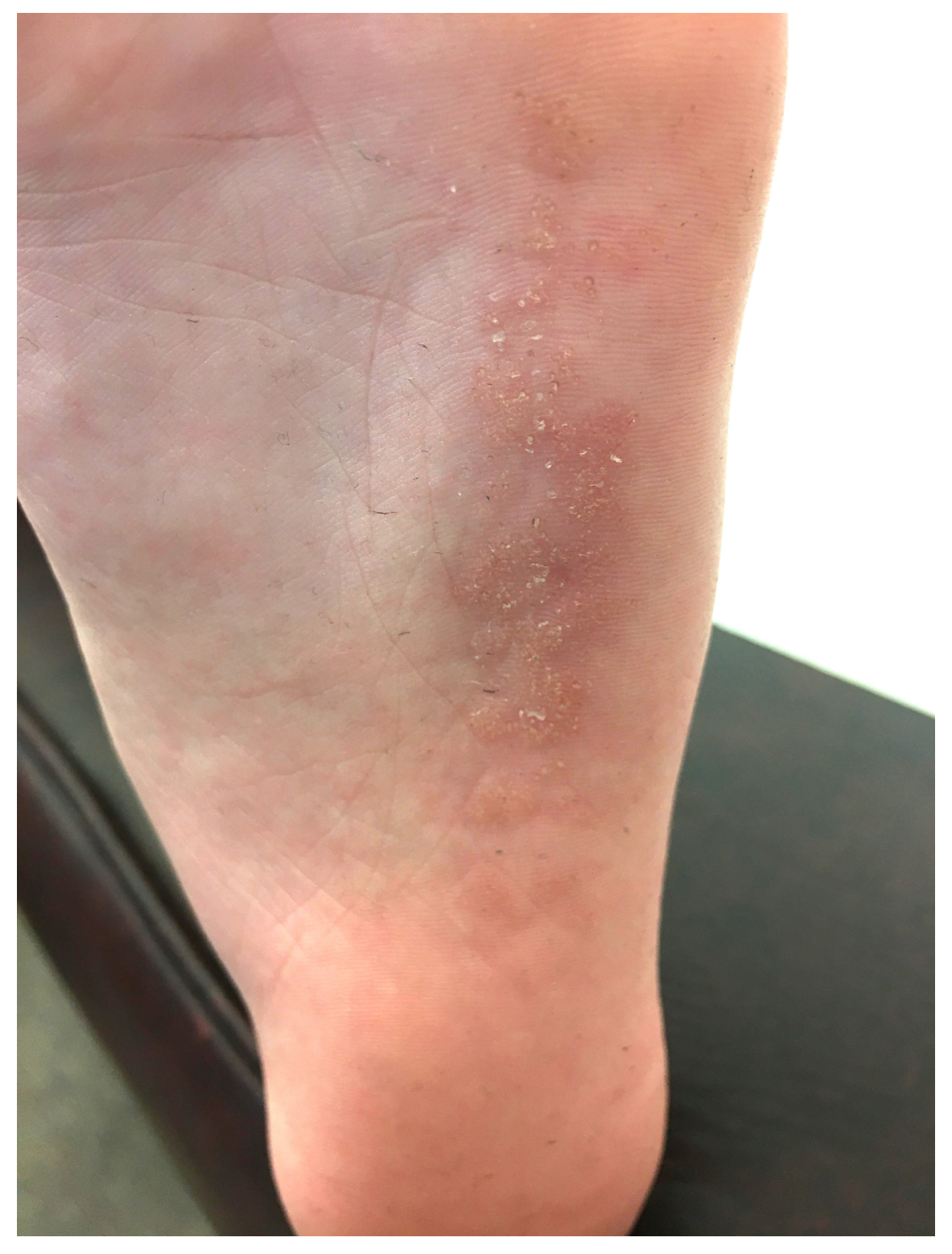




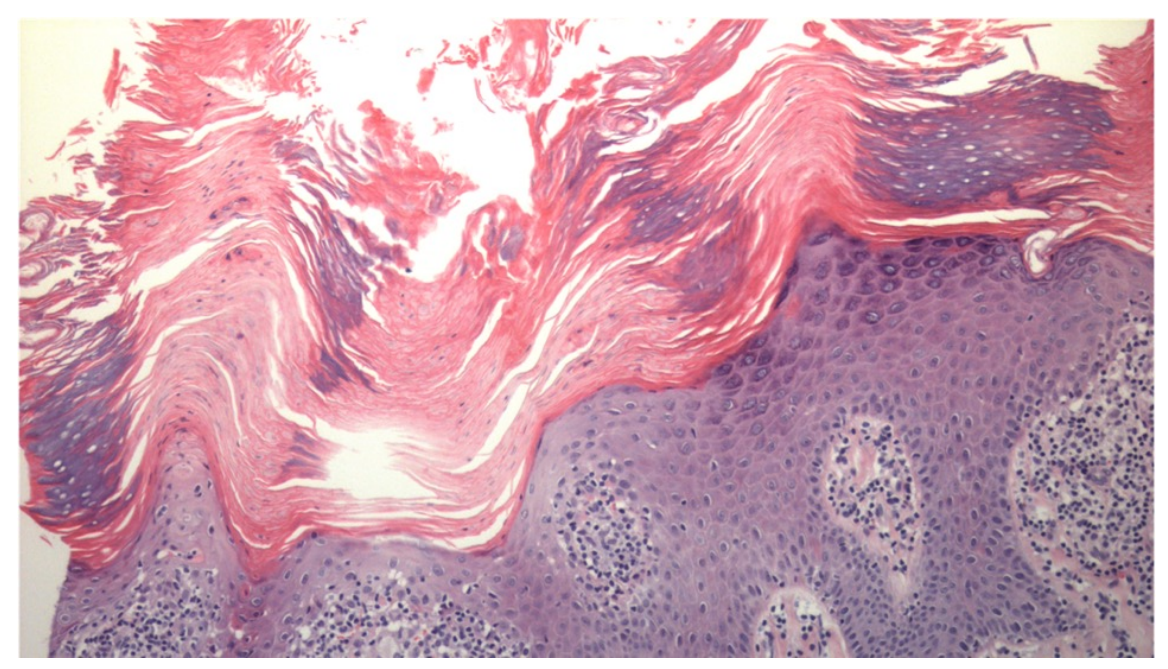

